\title{
A Fileira da Cortiça em Portugal - Posicionamento e Competitividade
}

\author{
Inocêncio Seita Coelho' ${ }^{1}$ Miguel Pestana ${ }^{2}$
}

Sumário. Portugal é o principal produtor e transformador mundial de cortiça. Esta posição foi assumida após a Guerra Civil de Espanha, em que Portugal ultrapassou aquele país na liderança mundial (DIAS, 2005).

A área ocupada pelo sobreiro, a nível mundial, situa-se próxima de 2,7 milhões de hectares (correspondendo a 350 mil toneladas de cortiça), distribuída essencialmente na zona Mediterrânea com influência atlântica. A Península Ibérica detém $56 \%$ da área total, Portugal com 33\% e Espanha com 23\% (PESTANA, 2005).

Portugal possui uma área com sobreiros de 713 mil hectares (DGRF, 2006). Em 83\% desta área, os povoamentos têm um estado de vitalidade bastante bom ou bom, com um apreciável potencial produtivo de cortiça amadia. Exportou 128.465 toneladas em 2001, com um valor de 880,8 milhões de euros. O país produz $54 \%$ da produção mundial de cortiça (em 2001 chegou a 340.000 toneladas), o peso da exportação desta matéria-prima é, aproximadamente, um quarto do total exportado pelo sector florestal e representa quase 3\% do cômputo das exportações totais (INE, 2006).

A importância estratégica do sobreiro e da cortiça, para Portugal, está reconhecida na Estratégia Nacional para as Florestas (DGRF, 2007).

Três países da União Europeia (Portugal, Espanha e Itália) são líderes na produção, transformação e comércio de cortiça. Portugal transforma quase 37\% do total mundial. As pequenas empresas são responsáveis pela transformação de $70 \%$ da produção nacional.

Por tudo isto, é fácil de entender a importância estratégica desta fileira para o nosso país, pelo que faremos um diagnóstico e uma análise prospectivos deste sector económico e utilizaremos uma análise SWOT para aferir a competitividade do mesmo. Palavras-Chave: Fileira da cortiça; vantagem competitiva; estratégia ; análise sWOT.

${ }^{1}$ Investigador Auxiliar c/Habilitação, ${ }^{2}$ Investigador Auxiliar. Instituto Nacional de Investigação Agrária e Veterinária, I.P. Av. da República, Quinta do Marquês, 2780-159 OEIRAS, Portugal.

E-mail: miguel.pestana@iniav.pt 


\section{The Cork Sector in Portugal - Positioning and Competitiveness}

Abstract. Portugal is the world's leading producer and processor of cork. This position was taken after the Spanish Civil War, in which Portugal overtook that country in the world leadership (DIAS, 2005).

The area occupied by the cork oak, worldwide, is close to 2.7 million hectares (corresponding to 350 thousand tons of cork), distributed mainly in the Mediterranean area with Atlantic influence. The Iberian Peninsula holds $56 \%$ of the total area, Portugal with 33\% and Spain with 23\% (PESTANA, 2005).

Portugal has an area with cork oaks of 713 thousand hectares (DGRF, 2006). In 83\% of this area, the stands have a very good or good vitality status, with an appreciable productive potential for amadia cork. It exported 128,465 tonnes in 2001, with a value of 880.8 million euros. The country produces $54 \%$ of the world production of cork (in 2001 it reached 340,000 tons), the weight of the export of this raw material is, approximately, a quarter of the total exported by the forestry sector and represents almost $3 \%$ of the total exports (INE, 2006).

The strategic importance of cork and cork, for Portugal, is recognized in the National Strategy for Forests (DGRF, 2007).

Three European Union countries (Portugal, Spain and Italy) are leaders in the production, processing and trade of cork. Portugal transforms almost $37 \%$ of the world total. Small companies are responsible for the transformation of $70 \%$ of national production.

For all these reasons, it is easy to understand the strategic importance of this sector for our country, so we will make a prospective diagnosis and analysis of this economic sector and use a SWOT analysis to gauge its competitiveness.

Key words: Cork; competitive advantage; strategy; SWOT analysis

\section{Le Secteur de Liège au Portugal - Positionnement et Compétitivité}

Résumé. Portugal est le premier producteur et transformateur mondial de liège. Cette position a été prise après la guerre civile espagnole, au cours de laquelle le Portugal a dépassé ce pays dans le leadership mondial (DIAS, 2005).

La superficie occupée par le chêne-liège, dans le monde, est de près de 2,7 millions d'hectares (correspondant à 350000 tonnes de liège), répartis principalement dans la zone méditerranéenne d'influence atlantique. La péninsule ibérique occupe $56 \%$ de la superficie totale, le Portugal 33\% et l'Espagne 23\% (PESTANA, 2005).

Le Portugal a une superficie de 713000 hectares de chênes-lièges (DGRF, 2006). Dans $83 \%$ de cette superficie, les peuplements ont un très bon ou bon état de vitalité, avec un potentiel productif appréciable de liège amadia. Elle a exporté 128465 tonnes en 2001, pour une valeur de 880,8 millions d'euros. Le pays produit $54 \%$ de la production mondiale de liège (en 2001 il atteignait 340000 tonnes), le poids de l'exportation de cette matière première est, environ, un quart du total exporté par le secteur forestier et représente près de $3 \%$ de la exportations totales (INE, 2006). 
L'importance stratégique du liège et du liège, pour le Portugal, est reconnue dans la stratégie nationale pour les forêts (DGRF, 2007).

Trois pays de l'Union européenne (Portugal, Espagne et Italie) sont leaders dans la production, la transformation et le commerce du liège. Le Portugal transforme près de $37 \%$ du total mondial. Les petites entreprises sont responsables de la transformation de $70 \%$ de la production nationale.

Pour toutes ces raisons, il est facile de comprendre l'importance stratégique de ce secteur pour notre pays, nous allons donc faire un diagnostic et une analyse prospectifs de ce secteur économique et utiliser une analyse SWOT pour mesurer sa compétitivité.

Mots-clés: Liège; avantage compétitif; stratégie; analyse SWOT 
76 Coelho, I.S. e Pestana, M.

\section{Introdução}

A análise SWOT e vantagem competitiva

O tema estratégia sofreu modificações ao longo do tempo, sendo possível distinguir dois momentos: o posicionamento e o movimento.

No primeiro, ela é associada a princípios de adaptação e posicionamento, ou seja, ela pressupõe uma adaptação à envolvente para assim adquirir uma posição dominante e proceder, seguidamente, à sua defesa. Este momento inicia-se com a análise SWOT ("Strengths", "Weaknesses", "Oportunities", "Threats") ${ }^{1}$, possibilitando uma reflexão sobre as suas vantagens competitivas, de acordo com a metodologia de Michael Porter. (DÉTRIE, 1993)

No segundo momento assume-se como uma ruptura, colocando em evidência uma estratégia centrada na intenção e no movimento, onde é visada a transformação permanente do jogo concorrencial. (DÉTRIE, 1993)

Assim, ficaremos pelo primeiro momento - posicionamento da fileira da cortiça -, onde faremos uso dos conceitos, a análise SWOT e vantagem competitiva, que nos permita diagnosticar uma estratégia para a fileira da cortiça.

Os fundamentos da análise SWOT, que remontam aos anos de 1950, preocupam-se com a integração das actividades da empresa, onde é dada a resposta à questão, "em que negócios nós estamos?" (SOUSA, 1993)

Peter Drucker foi o primeiro a levantar esta questão, confirmando assim a importância futura das decisões tomadas hoje e a necessidade de termos um propósito. (SOUSA, 1993)

Mais tarde, Igor Ansoff e Kenneth Andrews apresentaram uma outra visão sobre o conceito estratégia dos processos, a abordagem holística, segundo a qual esta deveria ser formulada e implementada, e onde a empresa deveria ser vista como um todo e não de uma forma fragmentada, ou seja, função a função (SOUSA, 1993).

Foram Kenneth Andrews e Roland Christensen que desenvolveram o primeiro modelo de análise estratégica, a que deram o nome de Análise SWOT, que se traduz por uma inventariação das forças e fraquezas da empresa e das oportunidades e ameaças da envolvente a esta, conduzindo-nos assim a uma interrogação sobre o perfil concorrencial, que compare as forças e fraquezas da empresa relativamente aos seus concorrentes. (DÉTRIE, 1993)

\footnotetext{
1 Análise TOFA - Trunfos, Oportunidades, Fraquezas e Ameaças.
} 
À medida que os trabalhos sobre o perfil concorrencial assumiam um carácter sistemático, iniciou-se uma busca dos elementos que pudessem ser simultaneamente sólidos e duráveis, o que designamos por vantagem competitiva.

Nos anos 80 do século passado, Michael Porter cria uma outra metodologia de análise, onde a estrutura de uma indústria determina as regras da competição entre empresas e influencia a estratégia a seguir. A intensidade da concorrência depende das seguintes cinco forças:

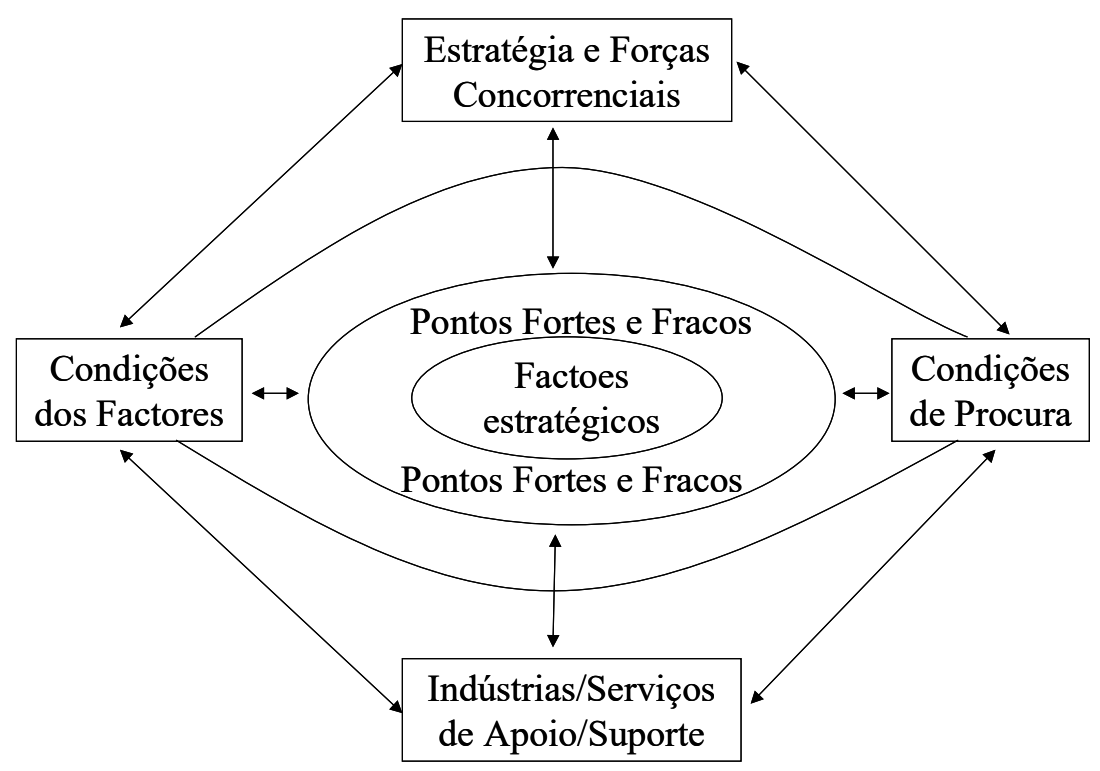

Figura 1 -

\section{Ameaça de novas entradas}

A entrada de novos concorrentes numa indústria conduz, em regra, a três consequências:

-Uma disputa pela conquista de quota de mercado;

- O aumento significativo da capacidade de produção;

-A maior aplicação de recursos nessa indústria. (PORTER, 1989; 1994)

Assim, a entrada de novos concorrentes deve ser tomada em conta, já que é uma ameaça para os actuais competidores. 
78 Coelho, I.S. e Pestana, M.

Porter identificou as seguintes barreiras à entrada:

- Economias de escala;

- Diferenciação do produto;

- Necessidades de capital;

- Custos de transferência;

- Política do governo;

- Retaliação esperada;

- Outras economias de custo (existência de patentes, acesso favorável a matérias-primas, subsídios governamentais e/ou economias de experiência). (PORTER, 1989; 1994)

\section{$\underline{\text { Rivalidade entre competidores }}$}

As empresas dispõem de armas - preço, publicidade e novos produtos - para vencerem a "guerra" da competitividade. É, pois, importante saber escolher essa arma para fazer face ao rival. O conjunto de factores que causa essa rivalidade é:

-Elevado número de competidores ou grande equilíbrio de forças entre eles;

- Crescimento lento dessa indústria;

-Custos fixos ou de armazenamento elevados;

-Aumentos bruscos de capacidade produtiva;

-Diversidade do número de concorrentes, mas também da sua qualidade;

-Importância estratégica do negócio;

•Elevadas barreiras à saída. (PORTER, 1989; 1994)

\section{$\underline{\text { Produtos substitutos }}$}

Todas as empresas numa indústria estão em concorrência com as que produzem produtos substitutos, i. e., a ameaça da substituição consiste na troca de um serviço ou produto por outro que satisfaça as mesmas necessidades. (PORTER, 1989; 1994)

O consumidor irá beneficiar pois haverá uma melhor relação preçoqualidade.

\section{$\underline{\text { Poder de negociação dos clientes }}$}

Os consumidores e os fornecedores também competem e influenciam a indústria, uma vez que têm o poder de forçar as variações de preços.

A força negocial dos clientes é maior quando: 
- As suas compras têm grande impacto nas vendas da empresa, obrigando à diminuição dos preços dos produtos comprados e ao aumento da exigência na qualidade desses produtos ou fomentando a concorrência entre os intervenientes;

- Os produtos que compram são pouco diferenciáveis;

- Os custos inerentes à mudança de clientes são bastante elevados;

- Constituem uma ameaça de integração a montante. (PORTER, 1989; 1994)

\section{$\underline{\text { Poder de negociação dos fornecedores }}$}

Por outro lado, os fornecedores podem exercer o seu poder sobre uma indústria quando ameaçam subir os preços ou reduzir a qualidade dos seus produtos ou serviços.

Quanto maior for o custo de transferência, mais o cliente está dependente do seu fornecedor. Estes ganham mais poder negocial nas seguintes condições:

- Existem poucos "rivais" a concorrerem no mesmo mercado, já que o nível de concentração é superior ao dos clientes;

- Não há produtos substitutos ou não estão disponíveis rapidamente;

- A indústria a abastecer não constitui um cliente importante, pois adquire apenas uma pequena fracção do total dos produtos do fornecedor;

- Os produtos fornecidos são diferenciáveis e/ou existem custos de transferência (mudança) elevados;

- Constituem uma ameaça a integração a jusante. (PORTER, 1989; 1994)

Para além deste modelo de análise é necessário verificar a atractibilidade da indústria (medida pelos indicadores financeiros), identificar os factores críticos para o sucesso do negócio e confrontá-los com os pontos fortes e fracos das empresas.

Só assim é que é possível dar o passo para a escolha de uma estratégia de acordo com as vantagens concorrenciais de que as empresas dispõem.

\section{Caracterização da fileira da Cortiça}

Em Portugal a floresta ocupa 39,3\% do território continental (3 490000 ha), onde cerca de $49 \%$ dessa área está inserida em explorações agrícolas, estando $70 \%$ dessa área ocupada com montados de sobro e azinho. A maior parte destes montados estão incluídos em unidades produtivas de grandes dimensões localizadas no Sul. Os 30\% remanescentes estão inseridos em unidades de 
pequena ou muito pequena dimensões, localizadas no Norte e Centro. Sabendose que a floresta privada das indústrias de celulose já atinge os 250000 ha, a floresta pública 86000 ha e a floresta comunal 264000 ha, pode-se afirmar que a estrutura da propriedade florestal é dominada pela floresta privada não industrial que representa $82,8 \%$ do total. As florestas pública e comunal detêm uma quota de $10,0 \%$ e a floresta privada de empresas da indústria da celulose e do papel alcança 7,2\% do total (Quadro 1).

Em relação ao sobreiro, a estrutura por tipo de propriedade é bastante diferente. As propriedades do tipo pública e comunal detêm $0,4 \%$, as empresas de celulose e pasta de papel dominam 1,4\%, enquanto que a propriedade privada não industrial possui $98,2 \%$ do total da área do sobreiral português.

Quadro 1 - Floresta e montado de sobro segundo o tipo de propriedade

\begin{tabular}{|l|c|c|c|c|}
\hline \multicolumn{1}{|c|}{ Tipo } & $\begin{array}{c}\text { Á. Florestal } \\
\text { (ha) }\end{array}$ & $\%$ & $\begin{array}{c}\text { Á. de sobro } \\
\text { (ha) }\end{array}$ & $\%$ \\
\hline Pública e comunal & 350000 & 10,0 & 2860 & 0,4 \\
\hline Privada de industrias & 250000 & 7,2 & 10000 & 1,4 \\
\hline Privada não industrial & 2890000 & 82,8 & 700140 & 98,2 \\
\hline Total & 3490000 & 100,0 & 713000 & 100,0 \\
\hline
\end{tabular}

Fontes: CELPA e Inventário Florestal (2003)

O sobreiro em Portugal está maioritariamente na posse de proprietários privados e localiza-se fundamentalmente nas regiões do Ribatejo e do Alentejo. Pode-se aceitar que a estrutura da propriedade privada nessas regiões é o espelho da estrutura da propriedade do sobreiral nessas mesmas regiões.

Neste último meio século, a área de sobro em Portugal cresceu 9,5\% (tomando por base a existente em 1955), correspondendo a uma taxa de crescimento média anual de $0,2 \%$, pelo que serão necessários 500 anos para duplicar a área existente em 1955, caso se mantenha este ritmo de crescimento (Quadro 2), o que dá uma ideia da diferença de ritmo verificada entre 1900 e 1950 e depois desta data até 2000 .

Quadro 2 - Evolução da área de sobro na 2a metade do século XX

\begin{tabular}{|l|c|c|}
\hline \multicolumn{1}{|c|}{ Ano } & Área (1000 ha) & $\Delta$ acumulado médio \\
\hline $1955^{*}$ & 651 & - \\
\hline $1970^{* *}$ & 656 & 0,77 \\
\hline $1985^{* *}$ & 664 & 2,0 \\
\hline $2003^{* *}$ & 713 & 9,5 \\
\hline
\end{tabular}


Pela análise do Quadro 2 é possível constatar que esse crescimento não foi homogéneo ao longo de todo o período. Entre 1955 e 1970, a taxa média de crescimento anual foi de 0,05\%, até 1985 essa taxa situou-se em $0,07 \%$ anuais e em 2003 subiu para 0,2\% como já referimos. No período de 1985 a 2003, ocorreu um aumento significativo da área de sobreiro.

Dados avançados no último Congresso Mundial do Sobreiro e da Cortiça realizado em 2000 em Lisboa (MADRP, 2000) permitem-nos ter uma noção da área de distribuição mundial do sobreiro (Quadro 3). Procedemos à correcção dessa área a partir dos dados constantes no Inventário Florestal de 2003 e em GIL (2005).

Quadro 3 - Distribuição mundial do sobreiro

\begin{tabular}{|l|c|c|c|c|}
\hline \multicolumn{1}{|c|}{ País } & Área (ha) & \% & Área corrigida (ha) & \% \\
\hline Portugal & 725000 & 33 & 713000 & 30.7 \\
\hline Espanha & 510000 & 23 & 488000 & 21.0 \\
\hline Argélia & 460000 & 21 & 460000 & 19.8 \\
\hline Marrocos & 198000 & 9 & 425000 & 18.3 \\
\hline Itália & 225000 & 10 & 90000 & 3.9 \\
\hline Tunísia & 60000 & 3 & 60000 & 2.6 \\
\hline França & 22000 & 1 & 85000 & 3.7 \\
\hline Total & 2200000 & 100 & 2321000 & 100 \\
\hline
\end{tabular}

Fontes: *APCOR (2003), Inventário Florestal (2003), GIL (2005)

A produção reflecte diferenças de produtividade, mas, acima de tudo, reflecte a existência de sobreiral não produtivo, onde não há extracção de cortiça. Para uma produção mundial média de 300000 toneladas, a repartição é feita de acordo com o exposto no Quadro 4.

Quadro 4 - Produção mundial média de cortiça por país

\begin{tabular}{|l|c|}
\hline País & $\%$ \\
\hline Portugal & 55 \\
\hline Espanha & 26 \\
\hline Itália & 6 \\
\hline Marrocos & 5 \\
\hline Argélia & 4 \\
\hline Tunísia & 3 \\
\hline França & 1 \\
\hline Total & 100 \\
\hline
\end{tabular}

Fonte: APCOR (2003) 
Os países da Península Ibérica que detêm 52, $7 \%$ da área de sobreiro produzem em média $81 \%$ do total, enquanto que os países do Norte de África, com mais de um terço da área, só produzem 12 \% do total (MADRP, 2000).

Em Portugal há a referir que a estrutura da propriedade dos montados de sobro é dominada por propriedades de média e grande dimensão para o referencial da propriedade rústica do país (COELHO, 2000). A maior parte da mão-de-obra empregada é assalariada, sendo pouco expressiva a utilização de mão-de-obra familiar. Na realização de determinadas tarefas, nomeadamente novas florestações, limpeza de mato e construção de infra-estruturas, é cada vez mais frequente o recurso aos serviços prestados por empresas especializadas.

Em montados maduros as tarefas implicam uma maior utilização de mão-deobra do tipo assalariado, sendo a extracção da cortiça e o tratamento do gado as tarefas que empregam mão-de-obra de forma mais intensa.

A partir de dados obtidos em contabilidades de diversas unidades de produção podemos chegar a números médios que apontam para $0,2 \mathrm{dH} /$ ha de sobreiral na extracção da cortiça. O grupo de extracção da cortiça é, normalmente, composto pelo capataz, que é quem dirige o grupo, por 10 tiradores, um tractorista, a coqueira (tem por tarefa preparar as refeições) e um marcador, a quem compete ir marcando o ano de extracção nas árvores descortiçadas.

Considerando a mão-de-obra utilizada nos serviços adquiridos, na guarda da propriedade e na conservação de infraestruturas, a intensidade de emprego de mão-de-obra varia entre $1,8 \mathrm{dH} /$ ha de SAU e $2,5 \mathrm{dH} /$ ha de SAU, conforme seja mais ou menos intensivo o tipo de sistema de produção (COELHO, 1996).

Aplicando esses valores ao conjunto da área ocupada pelo sobreiro podemos chegar a um valor total de emprego de mão-de-obra de 5300 a $5500 \mathrm{dH}$ por ano.

Relativamente à actividade da indústria, ela reparte-se por três grandes áreas: preparados, transformados e aglomerados.

A rolha de cortiça continua a ser o principal produto final, pois o seu valor representa quase $60 \%$ do produto final (PESTANA, 2005).

Todavia, nota-se uma tendência para a diminuição do peso relativo da produção de rolhas em contrapartida a um acréscimo da produção de aglomerados. Em 2003 o valor da totalidade dos produtos aglomerados relativamente ao das rolhas de cortiça natural era de duas vezes e meia superior ao destas.

A matéria-prima consumida de origem nacional é de 63\% (ano de 2000), tendo o volume de cortiça consumida vindo a aumentar. Depois de $160 \mathrm{mil}$ 
toneladas em 1980, a cortiça laborada ultrapassa hoje as 230 mil toneladas. (PESTANA, 2005)

A evolução da oferta e procura interna de cortiça tem sido cíclica na perspectiva da produção anual, originando uma consequente retracção do consumo desta matéria-prima pela indústria, uma vez que a cortiça importada é, em geral, de pior qualidade relativamente à nacional (PESTANA-SILVA, 2004).

Em Portugal existem mais de 1000 empresas transformadoras de cortiça.

O consumo mundial de cortiça tende a aumentar, designadamente para isolamento e revestimento na construção de edifícios e em outras aplicações, quer de cortiça em prancha, quer de aglomerados e granulados que permitem o aproveitamento de aparas, desperdícios e refugo (PESTANA-SILVA, 2004; PESTANA, 2005).

Entre os problemas que se colocam à indústria corticeira nacional ressaltam, desde logo, os que respeitam à quantidade, qualidade e preço da matéria-prima. As elevadas margens de intermediação da cortiça oneram o produto final, embora se tenha verificado nos últimos anos uma melhoria nos circuitos de comercialização (PESTANA-SILVA, 2004).

A taxa de investimento tem vindo a aumentar, já que há uma crescente concorrência externa que tem incentivado a investigação e desenvolvimento (I\&D) e a modernização da indústria, tanto em termos tecnológicos como na valorização dos recursos humanos. Este facto torna-se mais notório em algumas empresas com maior capacidade financeira, que desenvolvem projectos nessa área.

Quanto ao comércio externo desta indústria, temos a referir que Portugal exportou em 2004 um volume superior a 150 mil toneladas de cortiça, que renderam mais 890 milhões de euros (DGRF, 2006).

A cortiça em bruto ou semi-laborada (prancha, placas, blocos) tem um peso diminuto e cada vez menor nas exportações; exportam-se produtos com maior valor acrescentado. A exportação destes tem vindo a aumentar em termos percentuais graças aos aglomerados para isolamento (aglomerado negro), para revestimento e outros fins, como é o caso dos painéis decorativos, incluindo também rolhas (aglomerados brancos). A indústria de aglomerados negros tem algumas limitações competitivas, uma vez que existem diversos concorrentes na construção civil, estando em declínio, ao contrário dos aglomerados brancos, de cortiça de $1^{a}$ qualidade, que tem vindo a ganhar mercados em novas aplicações (PESTANA-SILVA, 2004). 
As características da matéria aconselham a indústria transformadora a localizar-se junta da produção. De facto, é assim, como se pode comprovar no Quadro 5.

Quadro 5 - Estrutura da Indústria Mundial de Transformação de Cortiça

\begin{tabular}{|l|c|}
\hline País & \% \\
\hline Portugal & 50 \\
\hline Espanha & 25 \\
\hline Outros produtores & 10 \\
\hline Não produtores & 15 \\
\hline Total & 100 \\
\hline Fonte: APCOR (2003)
\end{tabular}

Nos países da Península Ibérica transforma-se $75 \%$ da matéria-prima mundial, nos outros países produtores de matéria-prima (Norte de África, Itália e França) transforma-se $10 \%$ do total e em países não produtores transforma-se $15 \%$ da cortiça mundial (Leste europeu, Suíça, Alemanha, Reino Unido, EUA, e outros).

A rolha é o produto principal da transformação da cortiça, mais de $60 \%$ do total é destinada à produção de rolhas e o restante destina-se principalmente à produção de aglomerados (33\%) e granulados (6\%).

Em Portugal, o maior exportador mundial de produtos transformados de cortiça, $90 \%$ do volume dos produtos transformados, destina-se ao mercado externo, sendo $75 \%$ referente a rolhas.

Portugal exporta, por ordem decrescente, para França, Alemanha, Estados Unidos da América, Espanha e Austrália que, em conjunto, absorvem quase 65\% do total das exportações portuguesas (MARQUES, 2006). Outros países importadores com algum significado são o Reino Unido, Suiça, Japão, Áustria, Chile, África do Sul, Argentina e Holanda, que no conjunto absorvem 23\% do volume das exportações portuguesas, os restantes $12 \%$ têm como destino vários países, com destaque para os do Leste Europeu.

O consumo de rolha está a atravessar um período de retracção, com quebra significativa nas exportações, devido ao aparecimento de vedantes alternativos, como a rolha sintética, e ao uso de outro tipo de recipientes alternativos ao vidro, como as embalagens tipo tetrapak. Está a diferenciar-se uma gama de vinhos de consumo corrente em que se opta pela utilização de outras formas de embalagem mais baratas que o vidro e a cortiça, que são contudo imbatíveis nos vinhos de alta qualidade. 
Os produtos transformados com utilização na construção civil têm um mercado em expansão.

Os preços da cortiça já reflectem estas tendências dos mercados mundiais. A cortiça de melhor qualidade, que é mais valorizada, destina-se à produção de rolha que, como vimos, está em retracção; a cortiça de menos qualidade vai para as outras transformações, que estão em expansão mas que valorizam menos as cortiças. Assim, de um máximo de preços da cortiça na pilha que atingiu os 75 euros por arroba no começo do século XXI está agora a 55 euros por arroba, reflectindo nos últimos 3 anos quebras de cerca de um terço.

A quebra na procura da rolha criou outra situação inédita nesta última campanha em que inúmeros produtores de cortiça têm a produção na pilha sem compradores, um facto inédito que está a causar alguma apreensão aos produtores de cortiça em Portugal.

Portugal tem vindo a importar um volume considerável de cortiça em bruto (dada a escassez relativa de matéria-prima), designadamente de Espanha, donde se importa a quase totalidade da cortiça, e de Marrocos. O volume total de cortiça importada atinge já 50 mil toneladas, cerca de 1/3 do volume exportado, ainda que seja próximo dos $9 \%$ do valor total exportado (79658 milhões de euros em 2004). Convém esclarecer que a importação é um fenómeno que se pode considerar histórico e mesmo estratégico, dado que actua como meio de controlo da produção e da comercialização mundial deste produto.

Em Portugal, que domina o comércio mundial de cortiça, as exportações têm vindo a aumentar ligeiramente em volume, apesar de se apontar a falta de uma estratégia global na actuação das empresas nacionais, desde a produção à comercialização. Verifica-se, em muitas empresas, uma desactualização tecnológica nos processos de transformação, com reflexos na aceitação dos produtos em mercados mais exigentes.

Um dos principais problemas da comercialização da cortiça no exterior diz respeito aos intermediários externos (armazenistas) que conduzem a distribuição. Só os maiores produtores e exportadores começam a organizar as suas próprias redes de distribuição, reconhecendo-se uma melhoria dos canais de distribuição nos últimos anos (PESTANA-SILVA, 2004).

Assim, a perspectiva da fileira da cortiça, mais exactamente da indústria da cortiça, apresenta-se com problemas ao nível da oferta, pela insuficiência de matéria-prima de qualidade, pela inferior qualidade de alguns produtos, e também ao nível das redes de comercialização. Por seu turno, a procura interna de cortiça apresenta uma ciclicidade resultante da respectiva produção anual, o 
que leva a uma consequente retracção do consumo desta matéria-prima pela indústria, dado que a cortiça importada é, em geral, de qualidade inferior à produzida no País.

A procura de cortiça natural ou de aglomerados brancos, provenientes de desperdícios de boa qualidade, tem vindo a crescer e a apresentar aplicações muito diferenciadas, tanto para isolamento como para revestimento. Por outro lado, a médio prazo, a concorrência com os sucedâneos às rolhas como vedantes de vinho de qualidade irá crescer.

Esta constatação vem ao encontro da ideia de PESTANA-SILVA (2004), que referia o interesse na realização de um estudo sistemático de diferentes classes de qualidade de cortiça em função de outras aplicações / utilizações e a sua aplicação potencial em termos industriais, como forma de diversificação de produtos e, ao mesmo tempo, reduzir a excessiva dependência na rolha de cortiça natural.

Assim, é de admitir um esforço de racionalização da indústria e uma melhoria nos circuitos de comercialização, mas não se espera um crescimento sustentado da oferta destes produtos nos próximos anos.

Em síntese, podemos referir que a cortiça utilizada maioritariamente no fabrico de rolhas é uma matéria-prima com potencialidades de aplicação muito diversificadas, principalmente em revestimento de interiores, dadas as suas características isolantes. Tem vindo a aumentar a procura de aglomerados de cortiça, que em certos casos substitui com vantagem a cortiça pura, na medida em que é um produto menos poroso e mais homogéneo, contribuindo para um maior nível de aproveitamento da matéria-prima.

\section{O Diagnóstico da fileira}

Como já foi referido, Portugal domina a produção e o mercado mundial da cortiça. Todavia, a indústria debate-se com várias dificuldades estruturais que vão desde a produção e extracção da cortiça até aos canais de distribuição, passando pela deficiente laboração do produto. Desde o início dos anos 80 intensificou-se uma crise já latente nos montados de sobro, caracterizada pela debilitação e, em certos casos, pela morte das árvores. O processo de extracção manual da cortiça tem contribuído para o agravamento da situação e para o encarecimento da matéria-prima. Como solução para este último problema já existe há vários anos a possibilidade de extraç̧ão mecânica da cortiça, a qual ainda precisa de ser melhorada, e cuja rendibilidade só será assegurada através 
de uma nova condução do sobreiro que privilegie o desenvolvimento da árvores com um tronco mais direito e com menos ramos.

No que se refere à laboração, esta está dividida em dois grupos de características técnicas e organizacionais diferenciadas: de um lado, um grupo empresarial que controla grande parte da produção e que dispõe de tecnologia e de redes de distribuição adequadas, e, de outro lado, um elevado número de pequenas empresas rolheiras, algumas sem condições de produção e comercialização e que, de um modo geral, oferecem produtos de menor qualidade.

A comercialização, quer da matéria-prima quer do produto final, é também deficiente por falta de organização e pelo conflito de interesses entre os respectivos produtores, estando muito dependente de intermediários nacionais e estrangeiros, o que também concorre para um preço final mais elevado. Os nossos produtos de cortiça são exportados para uma centena de países.

Factores de competitividade do sector

\section{O Contexto Externo}

A indústria corticeira tem uma grande interdependência entre os seus subsectores. Cada um apresenta determinadas características, o que torna mais complexa esta análise. Assim, faremos uma abordagem geral, identificando as características particulares de cada um dos subsectores.

I)Ameaças de novos concorrentes

Esta ameaça resulta da presença de barreiras à entrada e da retaliação dos concorrentes existentes.

As barreiras à entrada resultam de:

a) Economia de escala - dos 4 subsectores, só 2, o granulador e o aglomerador, apresentam um forte carácter mecanizado, tornando-se aqueles em que as economias de escala são significativas. $\mathrm{O}$ subsector transformador caracteriza-se por uma mecanização ainda menos difundida, podendo-se dizer que é o menos sensível a economias de escala. O subsector preparador, ainda que utilizando processos mecanizados, ao ter também uma forte componente de mão-de-obra, fica sujeito a menores economias de escala. 
b) Diferenciação de produtos - o subsector preparador, ao vender toda a sua produção aos restantes subsectores, apresenta uma reduzida diferenciação de produtos. Não há uma fidelização dos clientes devido, por exemplo, ao reconhecimento da marca. Resultando em produtos de uso industrial, a fidelização só se consegue através do reconhecimento da qualidade e dos preços concorrenciais. Tal facto existe porque, tendencialmente, alguns clientes começaram a exigir a certificação dos produtos da cortiça em toda a sua cadeia, o que fez com que as empresas preparadas para esta certificação ganhassem um novo alento concorrencial, um outro poder negocial. Nos restantes subsectores, o reconhecimento das marcas e a fidelização dos clientes já é uma realidade. Esta é bastante mais visível e importante no subsector aglomerador (essencialmente pelo tipo de produtos que produz e vende, bastante mais próximos do consumidor final).

c) Necessidades de capital - as necessidades de capital são elevadas nos subsectores granulador e aglomerador, essencialmente devido à forte mecanização e a maiores despesas de I\&D e de marketing. O subsector transformador apresenta as menores necessidades de capital, sendo exemplo disso a mortalidade e a natalidade de empresas neste subsector e a forte concorrência da economia informal.

d) Custos de mudança - embora a normalização seja uma realidade relativamente recente, ainda não está totalmente implementada. Todos os produtos apresentam alguma homogeneidade de características. Os custos de mudança poderão resultar mais de diferenças de qualidade do que por diferenciação de características.

e) Acesso a canais de distribuição - o subsector preparador vende directamente os seus produtos ao subsector transformador. Os subprodutos deste são vendidos ao subsector granulador, enquanto que os produtos principais são vendidos, na maioria dos casos, através de intermediários, que as maiores empresas da indústria corticeira dominam. Algumas empresas do subsector aglomerador já dispõem de canais de distribuição próprios.

f) Desvantagem de custo independentes da dimensão - as empresas já estabelecidas poderão gozar de alguma vantagem, essencialmente em termos de curva de experiência. Os registos das patentes são muito reduzidos, e o acesso privilegiado à matéria-prima cortiça só acontece por 
uma maior capacidade financeira. A localização parece nunca ter constituído um óbice, pelo que também aqui a vantagem é reduzida.

g) Política governamental - as restrições governamentais residem essencialmente na protecção ao sobreiro, evitando a sobreexploração e protecção ambiental.

Do que foi dito, pode-se concluir que as barreiras à entrada variam de subsector para subsector. São elevadas nos subsectores granulador e aglomerador e relativamente baixas nos restantes subsectores (principalmente no subsector transformador, daí a sua sobrecapacidade).

Por outro lado, nesta indústria, a retaliação dos concorrentes verifica-se em algumas empresas que possuem avultadas reservas, acarretando uma concorrência ao nível de preços elevada. No entanto, o factor mais diferenciador nesta indústria talvez seja a existência de reservas, concentrado num pequeno grupo de empresas integradas verticalmente (e horizontalmente), com uma forte relação com o subsector rolheiro, e que, ao influenciarem os preços praticados, acabam por afectar todos os outros subsectores. Dada a característica de irracionalidade competitiva do sector, acabam por ser as barreiras de entrada determinantes da maior ou menor facilidade de entrada de novos concorrentes.

Da conjugação das barreiras à entrada e da intensidade da retaliação, conclui-se pela maior ameaça de novos concorrentes nos subsectores preparador e transformador. Os restantes subsectores - aglomerador e granulador apresentam uma situação bastante favorável à entrada de novos concorrentes.

\section{II) Poder Negocial dos Fornecedores}

Os fornecedores podem afectar a indústria através da sua capacidade para aumentar os preços ou diminuir a qualidade. Algumas das características determinantes do forte poder de negociação dos fornecedores já foram anteriormente referidas, pelo que faremos a inclusão somente dos fornecedores de matéria-prima de cortiça - a indústria preparadora - que fornece directamente uma parte da indústria. A oferta de produtos suberícolas é muito inferior ao nível actual da procura por parte da indústria. Por outro lado, existem já disponíveis produtos substitutos. Quanto aos preços da cortiça no mato, estes são resultantes de cotações dos produtos acabados no mercado internacional, nomeadamente da rolha de cortiça natural, não sendo o produto capaz de impor os seus preços. Neste sentido, pode concluir-se que o poder de negociação é fraco. No entanto, é de notar que a qualidade de toda a indústria 
depende de vários factores, alguns deles resultantes da acção do produtor suberícola, pelo que este poderá adquirir importância quando a qualidade da cortiça no mato passar a ser devidamente avaliada e valorizada (o que começa a ser uma realidade, com a crescente exigência de certificação). No entanto, esta lógica cai pela base quando entram em jogo irracionalidades concorrenciais, frequentes na indústria, que resultam não só de alarmismos de menor produção suberícola, como também da valorização não sustentada dos preços da cortiça, determinadas pelas maiores empresas, com estratégias comerciais definidas. Nesta situação, o produtor adquire uma enorme importância, ao provocar o acompanhamento dos preços de aquisição de cortiça por todas as empresas (ou por aquelas que não têm outra opção se não comprarem).

Como é sabido de todos, toda a indústria depende largamente de um só produto, a rolha de cortiça natural, produzida no subsector transformador. Assim, este produto adquire especial notoriedade, quer como cliente do subsector preparador, quer como fornecedor aos restantes subsectores (granulador e aglomerador), sendo, desta forma, o subsector que impõe os preços.

III) Poder negocial dos clientes

Nesta indústria, os clientes são bastante mais concentrados que os seus fornecedores, designadamente ao nível do subsector rolheiro, o qual, por sua vez, impõe forte dependências aos outros subsectores.

As reduzidas barreiras à entrada e de retaliação esperadas neste subsector, aumentam o espectro de integração para montante por parte dos distribuidores. Por outro lado, os custos de mudança são essencialmente derivados da garantia de qualidade, para além do facto de que, em determinados segmentos e/ou produtos, existirem substitutos mais concorrenciais.

Pode-se, pois, concluir que os clientes externos à indústria detém um forte poder negocial (os internos são fortemente dependentes do subsector rolheiro).

IV) Ameaça de produtos substitutos

As grandes aplicações dos produtos de cortiça resumem-se a vedantes, isolantes e decorativos. Em todas estas aplicações existem diversos substitutos, desde a rolha de borracha (vedante), lã de vidro (isolador), até ao mármore (decorador). A menor ou maior ameaça dos produtos substitutos depende do posicionamento dos produtos da cortiça nas diversas aplicações. Por exemplo, 
os discos de cortiça como vedantes das cápsulas metálicas foram já praticamente substituídos por discos plásticos, com resultados semelhantes, de mais fácil aquisição e com custos inferiores. No entanto, as rolhas de cortiça natural constituem o único vedante dos vinhos de qualidade média e superior, tendo surgido nos últimos anos uma maior procura para este segmento. A substituição far-se-á tanto quanto menores forem as diferenças técnicas e de qualidade, sendo igualmente uma questão de moda e design. O preço joga também um papel importante, sobretudo quando o produto representa uma fatia significativa das compras do cliente, se este for menos sensível às questões da qualidade e se apresentar baixa rentabilidade.

A rolha de cortiça natural dispõe de uma posição claramente dominante, enquanto os outros produtos não detêm uma posição tão sólida. A razão está no facto de a rolha de cortiça natural não ter sucedâneos como vedante de vinhos de qualidade, ao contrário do que acontece com os demais produtos.

V) Rivalidade entre competidores

$\mathrm{Na}$ intensidade registam-se os seguintes factores:

-O sector da cortiça é caracterizado por um elevado número de unidades de pequena dimensão (com excepção das grandes empresas que são em número reduzido);

- Os aumentos das vendas poder-se-ão efectuar à custa do aumento da produção de vinho ou da diminuição das vendas dos outros concorrentes, entre outras. A indústria da cortiça tem verificado taxas de crescimento bastante aceitáveis;

- Na indústria da cortiça ainda é generalizada a competição focalizada fundamentalmente pela prática de preços baixos;

-Se os custos fixos são elevados, as guerras entre a concorrência poderão ser uma realidade. Os subsectores granulador e aglomerador poderão apresentar essa característica;

-A existência de barreiras à saída também constitui um importante factor de rivalidade. A especificidade dos equipamentos determina estas barreiras, bem como a lealdade dos gestores ao negócio.

Assim, podemos concluir, que:

A fileira da cortiça caracteriza-se por uma elevada ameaça de novos concorrentes nos subsectores preparador e transformador, um elevado poder de negociação de fornecedores de cortiça como matéria-prima e dos fornecedores 
de matéria-prima para o subsector granulador e aglomerador (subsector rolheiro), um elevado poder de negociação dos clientes, uma forte ameaça de produtos substitutos que, em muitos casos, já correspondem à sua quase substituição, bem como a uma intensa rivalidade entre concorrentes, designadamente entre as unidades do subsector rolheiro.

Verifica-se que o potencial de rendibilidade é baixo nos subsectores preparador e transformador (rolheiro), sendo mais elevado no subsector aglomerador. A manutenção da posição dos produtos de cortiça passará indiscutivelmente pela aposta na qualidade e no desenvolvimento de produtos de maior valor acrescentado.

\section{O contexto interno}

Estes factores constituem as forças e as fraquezas que determinarão se a fileira será capaz de tirar vantagem das oportunidades enquanto evita as ameaças.

Assim, a análise prospectiva está assente numa avaliação qualitativa das diferentes actividades que integram as condições de funcionamento das empresas, ou seja, na abordagem sectorial esteve subjacente o método acima referido - A Cadeia de Valor.

Análise prospectiva

\section{Condições da procura}

Na Dinâmica Procura destaca-se:

- procura com tendência crescente em exigências tecnológicas e de design;

- no sector rolheiro a tendência é de uma procura favorável, nomeadamente dos produtos transformados por simples talha - rolha de cortiça natural ;

- no segmento aglomerados as perspectivas são para um crescimento como reflexo da elevada procura de "parquets" de cortiça, rolos decorativos, "underlays" e pisos flutuantes com madeira e cortiça.

Por sua vez, na Sensibilidade aos Preços, temos a destacar o facto do sector não ter conseguido o aumento de preço dos produtos que seria de esperar. A diferenciação dos produtos, pela vertente ecológica e pela componente qualidade, está a dar os primeiros passos, o que irá permitir a sensibilização do consumidor relativamente ao aumento substancial do valor dos produtos.

Nos Mecanismos de Avaliação do Mercado há que referir: 
- os grandes grupos económicos, tanto no segmento rolheiro como no dos aglomerados, detêm conhecimento dos mecanismos da procura e domínio dos canais de distribuição dos produtos

- as PMEs (pequenas e médias empresas) trabalham de algum modo sob a estratégia dos grupos ou de empresas de comercialização;

- a maioria das restantes empresas desconhece os canais de distribuição e depende dos importadores estrangeiros, encontrando-se, pelo facto, desajustadas das regras do mercado externo, o que origina um desconhecimento das necessidades do cliente final por inexistência de contacto.

Por último, os factores Determinantes de Procura são a qualidade dos produtos, o marketing e o design.

\section{Condiç̃̃es dos factores}

a) Os Recursos Humanos:

Este sector possui, em geral, uma força de trabalho pouco qualificada, com baixos níveis de escolaridade e com dificuldades de adaptação a novas tecnologias. No entanto, ela é conhecedora das características da cortiça, como consequência dos muitos anos de experiência acumulada.

Embora exista um Centro de Formação Profissional para a Indústria da Cortiça (CINCORK) que desenvolve acções de formação de apoio ao sector, há uma enorme carência de formação profissional, sendo reconhecido o défice de técnicos de formação média-superior.

Por outro lado, a maior parte dos administradores são-no por uma questão de "herança" e não por formação, sendo que o nível etário destes é variado, o mesmo acontecendo com os trabalhadores; no entanto, tem-se verificado uma tendência de diminuição de idade média nos primeiros, com o aumento do nível de formação;

A qualidade de vida no trabalho é baixa, sendo também baixos os níveis salariais.

b) A Infra-estruturas Tecnológicas:

As empresas incluídas nos grandes grupos económicos dispõem de infraestruturas com capacidade técnica da investigação, nomeadamente laboratórios de ensaios acreditados. 
As pequenas unidades de produção estão ainda pouco sensibilizadas para a problemática da qualidade dos seus produtos. Todavia, algumas PMEs iniciam a caminhada na acreditação, criando também os seus laboratórios.

No âmbito do Sistema Português da Qualidade são de referir as actividades desenvolvidas pelo CTCOR - Centro Tecnológico da Cortiça, como Organismo Sectorial de Normalização e como Laboratório de Ensaio Acreditado.

c) Os Recursos de Capital:

Os grandes grupos económicos deste sector dispõem de capitais próprios adequados e de estruturas financeiras equilibradas. Todavia, as PMEs, em geral, têm falta de capitais próprios e dificuldades financeiras.

A grande maioria das empresas exibe uma estrutura débil, verificando-se, por outro lado, um número reduzido de grandes grupos económicos.

Nos últimos anos, algumas empresas ganharam dimensão através da integração vertical e mesmo horizontal, resultante do desaparecimento de muitas empresas ou da dificuldade financeira de outras.

\section{d) A Energia:}

Neste sector o custo da energia consumida não é significativo.

e) A Ciência e Tecnologia:

O nível de I\&D é bastante baixo, limitando-se primordialmente a I\&D de processo e secundariamente ao desenvolvimento de novos produtos. Por outro lado, a I\&D desenvolvida pelos centros de investigação centra-se, fundamentalmente, na caracterização da cortiça e na melhoria da qualidade.

\section{f) O Produto:}

As características dos produtos de cortiça são conhecidas, determinando as múltiplas aplicações. O reconhecimento das marcas começa a verificar-se, com realce para o segmento dos produtos aglomerados, onde o esforço das grandes empresas é notório. Contudo, este esforço ainda está longe da satisfação das necessidades do mercado nos aspectos da qualidade e estilo dos produtos de cortiça.

\section{g) A Distribuição:}

A grande parte dos produtos de cortiça é colocada através de intermediários, até no caso do produto de maior importância desta fileira - a rolha de cortiça natural. 
Com excepção das grandes empresas que possuem um departamento comercial (algumas destas até detêm participações nas empresas distribuidoras nos mercados de destino), é constatada a total dependência nos intermediários para o escoamento dos produtos transformados.

h) O Preço

A rolha natural tem sido a alavanca da valorização da cortiça, já que a formação de preços no mercado consumidor internacional reflecte o crescimento da procura deste produto e acompanha o crescimento do rendimento dos consumidores desses países (maioritariamente países desenvolvidos).

A política de preços visa assegurar a correcta valorização dos produtos, de forma a não comprometer o futuro a médio prazo. Os aumentos dos factores de produção têm vindo a repercutir-se, em parte, ao nível dos preços de venda, mas os ganhos têm sido obtidos nos produtos de maior qualidade, tentando dar alguma estabilidade aos preços, através de produtividade e de utilização da capacidade instalada, de modo a não comprometer os esforços em marketing e publicidade.

As práticas concorrenciais ao nível dos preços são usuais por parte das PMEs, originando desequilíbrios cíclicos e, assim, maiores ou menores dificuldades a essas empresas.

O segmento de aglomerados é competitivo, porque a valorização registada pela rolha de cortiça natural possibilita praticar preços baixos na cortiça que segue para a granulação.

i) Marketing e publicidade:

Esta indústria não tem uma gestão de marketing, sendo esta prática mais evidente nas PMEs.

Transparece uma postura de "andar a reboque" da sua envolvente concorrentes ou sectores a montante ou a jusante.

Contudo, os mercados utilizadores dos seus produtos são profissionais, o que obriga a um esforço na transmissão da informação através de publicidade publicações técnicas, feiras, promoções de produtos.

O utilizador final pouca ou nenhuma informação recebe sobre os produtos de cortiça; no entanto, é de referir a aproximação a estes por parte de algumas empresas. 
j) Operações no fabrico:

As técnicas de fabrico são sobejamente conhecidas. Porém, muitas delas encontram-se já antiquadas face às novas exigências em termos de qualidade $e$ produtividade. No entanto, tem-se verificado nos últimos anos, uma modificação na reorganização fabril de modo a responder apropriadamente estes aspectos.

\section{$\underline{\text { Indústrias de suporte }}$}

No tocante ao equipamento, há a referir que as unidades dos grandes grupos económicos se encontram bem apetrechadas tecnologicamente.

No segmento de transformação de rolhas, o parque de máquinas da maior parte das empresas é tecnologicamente ultrapassado e obsoleto, embora existam já algumas empresas com equipamentos actualizados Por outro lado, nos segmentos dos aglomerados utiliza-se tecnologia intensiva; no entanto, muitas empresas necessitam de actualização do seu parque máquinas

Podemos afirmar que é praticamente inexistente a produção nacional de equipamento específico para esta indústria, embora haja um pequeno grupo de empresas produtoras de maquinaria para a cortiça

b) Inputs

As matérias-primas consumidas são maioritariamente de origem nacional.

No segmento rolheiro, embora se tenha registado um ligeiro acréscimo da área de sobro, podem colocar-se problemas de matérias-primas, atendendo à escassez de matéria-prima de qualidade, resultante não só do actual estado de sanidade dos montados mas também das condições de tiragem da cortiça.

O segmento dos aglomerados utiliza como matéria-prima os desperdícios da fabricação das rolhas, rolhas com defeitos e refugo (cortiça de baixa qualidade) e, por isso, depende da quantidade e qualidade desses produtos

\section{Estratégias e forças concorrenciais}

a) Organização e características da Oferta

O tecido empresarial da indústria corticeira é bem distinto consoante se trate da produção de rolha ou de aglomerados, sendo, no seu conjunto, uma indústria exportadora.

Para a produção rolha predomina a empresa de pequena dimensão e fraca produtividade, enquanto que nos aglomerados, pelo contrário, existem 
unidades bem dimensionadas, com equipamentos modernos, resultantes de avanços tecnológicos registados nos últimos anos

$\mathrm{Na}$ área da comercialização tem vindo a aumentar a internacionalização, em particular no segmento dos pavimentos e revestimentos da cortiça. Tal facto é devido, em parte, à actividade desenvolvida pelo maior grupo industrial do sector, nomeadamente através da abertura de escritório e armazéns comerciais no estrangeiro.

No entanto, o segmento rolheiro tem também registado melhorias nas estruturas de comercialização, principalmente nos mercados externos.

b) Estratégias Empresariais

A estratégia empresarial da indústria da cortiça passa pelo reforço da presença das empresas nacionais nos circuitos de distribuição, pela sua capacidade de resposta às exigências a nível da qualidade dos produtos e pela garantia do sistema da qualidade.

\section{Matriz SWOT}

\section{Pontes Fortes}

- Grupos económicos nacionais

- Líder mundial de transformação e comercialização de produtos de cortiça

- Matéria-prima de qualidade com características técnicas únicas.

○ "know-how" do sector relativamente aos concorrentes internacionais

- Importância da fileira da cortiça na economia portuguesa.

\section{Pontos Fracos}

- Grande número de empresas de dimensão reduzida e tecnologicamente desactualizadas com uma estrutura rígida pouco apropriada à actualidade.

○ Mão-de-obra pouco qualificada

- Ausência de canais de comercialização próprios e forte dependência de intermediários externos, aliado à falta de imagem de marca.

- Baixa incorporação de I\&D no produto final e em inovação de novos produtos

- Política florestal desadequada ao sector e consequente sobreexploração do montado de sobro. 
Oportunidades

- Maior poder compra, associado à procura de matéria-prima de qualidade

- Crescente preocupação com os temas ambientais e energéticos relativos à utilização de produto natural e renovável.

- Novas técnicas de fabrico, com evidentes ganhos de produtividade e de rendimento de matéria-prima cortiça.

- Estabelecimento de relações formais com a o sector vinícola, de forma a valorizar a contribuição da rolha de cortiça natural na selagem de vinhos engarrafados.

- O combate à eliminação do Tricloroanisol (TCA) deve ser liderado pela indústria corticeira/rolheira.

- Aparecimento de novas áreas - a nível mundial (Austrália, América Norte e Sul e África do Sul) de produção de vinho. $\underline{\text { Ameaças }}$

O aparecimento de produtos substitutos competitivos

- Variações frequentes do preço de matéria-prima cortiça.

- Produção de vinhos de qualidade na Europa encontra-se estagnada.

- Incremento no cumprimento da legislação ambiental relativa à poluição, levando esta indústria a ser menos competitiva face à de produtos substitutos.

\section{Notas Finais}

Portugal domina indiscutivelmente a produção, transformação e o mercado mundial da cortiça.

Embora o montado português apresente alguma fragilidade, caracterizada pela debilitação e, em certos casos, pela morte de sobreiros, continua a deter um peso significativo na floresta portuguesa. Aqui, a actividade implica uma maior utilização de mão-de-obra, representando um valor total de emprego na ordem dos 5300 a $5500 \mathrm{dH}$ por ano, sendo a extracção da cortiça e o tratamento do gado as tarefas que empregam mão-de-obra de forma mais intensa. 
A produção de cortiça sustenta este sistema agro-florestal. Contudo, a extracção manual da mesma, que ainda hoje é muito vulgarizada, tem contribuído para o agravamento da situação de debilidade dos sobreiros (descortiçamentos pouco adequados) e para o encarecimento da matéria-prima. Como solução para este último problema, existe a possibilidade de extracção mecânica da cortiça, a qual permite um incremento da rendibilidade.

A indústria de preparação e transformação de cortiça é relevante na economia portuguesa, pelo seu peso nas exportações.

De facto, em 2004, as exportações desta indústria para uma centena de países, apresentam valores superiores a 150 mil toneladas de cortiça, que renderam mais 890 milhões de euros (DGRF, 2007), o que denota certa dinâmica e importância no comércio externo.

Todavia, a indústria corticeira apresenta algumas debilidades no âmbito da quantidade, qualidade e preço da matéria-prima, em particular este último aspecto. Tal facto causa uma elevada margem de intermediação, onerando o produto final, embora se verifique nos últimos anos uma melhoria nos circuitos de comercialização.

Constata-se que a mão-de-obra com emprego no sector é, em geral, pouco qualificada, sendo utilizada de forma mais intensa na preparação e produção de rolha, pelo que deve ser a alavanca para a reestruturação do sector que contrarie esta situação.

Nos últimos anos, a taxa de investimento nesta indústria tem vindo a aumentar, resultante de uma crescente concorrência externa, obrigando a modernização da indústria no campo tecnológico e a valorização dos recursos humanos.

No sector industrial está bem vincada a divisão em dois grandes grupos de características técnicas e organizacionais diferenciadas - um grupo empresarial que controla grande parte da produção e que dispõe de tecnologia e de redes de distribuição adequada e outro, com um elevado número de pequenas empresas rolheiras, algumas sem condições de produção e comercialização.

É importante também frisar a existência de substitutos para grande parte dos produtos de cortiça. Todavia, estes possuem propriedades únicas (rolha), características específicas (aglomerados negros), podendo mesmo ser apelativos na sua utilização (decorativos e 'parquet'), o que possibilita a satisfação de exigências de mercado que qualifiquem o produto.

Fica, deste modo, realçado que Portugal é o líder mundial na produção de cortiça e na transformação e comercialização desses produtos, possuindo os maiores grupos económicos neste sector e com um "know-how" muito superior 
100 Coelho, I.S. e Pestana, M.

aos concorrentes internacionais, devendo-se isso, em muito, à qualidade da matéria-prima.

\section{Bibliografia}

APCOR, 2003. Dados estatísticos provisórios.

COELHO, I., 1996. O montado a economia e o desenvolvimento do Alentejo. Silva Lusitana 4(1): 39-48.

COELHO, I., 2000. Proprietários e Mercado da Terra nas Regiões de Montado. O Caso do Concelho de Santiago do Cacém. Silva Lusitana 8(1): 61-74.

DÉTRIE, J.P., 1993. Strategor: Política Global da Empresa, Publicações D. Quixote, $1^{\mathrm{a}}$ ed, Lisboa.

DGRF, 2006. Inventário Florestal, Lisboa. http://www.dgrf.min-agricultura.pt/v4 Ldgf/pub.php?ndx=3733

DGRF, 2007. Estratégia Nacional para as Florestas, Lisboa.

DIAS, M.A., 2005. O impacto da fileira da cortiça no crescimento económico durante o estado novo (193-1974). Congrés Internacional Sureres, Fàbriques i Comerciants. Passat, Present $i$ Futur del Negoci Surer. Palafrugell (Girona).

Gil, L. 2005. Cortiça, da produção à aplicação. Câmara Municipal do Seixal.

Inventário Florestal, 2003, DGRF, Lisboa.

INE (Instituto Nacional de Estatística), 2006. Lisboa. http://www.ine.pt/pesquisa/ pesquisa.asp.

MADRP, 2000. O Sobreiro e a Cortiça. Um património universal, uma herança a preservar. Direcção Geral do Desenvolvimento Rural.

MARQUES, A., 2006. Evolução histórica da indústria corticeira. http://www.portalflorestal.com/canais/article.asp.

PESTANA, M., 2005. A Evolução do Sector Corticeiro em Portugal. Congrés Internacional Sureres, Fàbriques i Comerciants. Passat, Present i Futur del Negoci Surer. Palafrugell (Girona).

PESTANA-SILVA, M., 2004. A Caracterização da Qualidade da Cortiça para a Produção de Rolha. Aplicação de metodologia de análise multivariada com vista à validação de grupos de qualidade. Tese de Doutoramento UTAD, Universidade de Trás-os-Montes e Alto Douro, Vila Real.

PORTER, M., 1989, Vantagem Competitiva, Ed Campus, $5^{\text {a }}$ ed, Rio de Janeiro.

PORTER, M., 1994, Como descobrir as oportunidades de negócio, Exame Executive Digest 1(0):16-20.

SOUSA, A., 1993, Introdução à Gestão: Uma Abordagem Sistemática, Ed Verbo, $1^{\mathrm{a}}$ ed. Lisboa. 